Original Research Paper

\title{
Influence of Cadmium and Glucose on Soil Microbial Communities
}

\author{
Aliya Gilmullina, Polina Galitskaya and Svetlana Selivanovskaya \\ Institute of Environmental Sciences, Kazan Federal University, Kazan, Russian Federation
}

\author{
Article history \\ Received: 07-10-2015 \\ Revised: 03-11-2015 \\ Accepted: 05-11-2015 \\ Corresponding Author: \\ Aliya Gilmullina \\ Institute of Environmental \\ Sciences, Kazan Federal \\ University, Kazan, Russian \\ Federation \\ Email: monblan.pro@yandex.ru
}

\begin{abstract}
A laboratory-based simulation of exposure of the soil community in a gray forest soil to cadmium and glucose has been conducted. It was established that while growing in a fertile medium microbial communities isolated from a soil sample contaminated with cadmium have a substantially increased phase of growth delay and there is a reduction in total growth. While analyzing communities by Biolog Ecoplate method, it was found that, as compared to the community isolated from a soil rich in glucose, the community in a soil with cadmium is characterized by significantly lower $A W C D, R$ and $H$ indices, in which the differences increase with time of incubation. Also differences in the pattern and rate of recyclable substrates have been revealed. The resulting data suggest changes in the functional activity of the microbial community in the soil under the influence of cadmium.
\end{abstract}

Keywords: Biolog Ecoplate, Cadmium, Glucose, Soil

\section{Introduction}

Soil is a component of the biosphere performing important functions, including maintaining productivity. The rapid industrialization of society leads to the release significant amounts of pollutants, particularly metals, to land. The exhaust gases of vehicles, mining and smelting, precipitation are considered to be sources of pollution (Chabukdhara and Nema, 2013; Christoforidis and Stamatis, 2009; Kelepertzis, 2014; Wei and Yang, 2010; Zhao et al., 2014). Recently, soil contamination with metals is increased through the application of organic fertilizers, the placement of wastes on the land (Tejada et al., 2011; Vig et al., 2003). High toxicity of metals and their stability in the medium determines their impact on the soil microbial communities and the condition of ecosystems in general.

One of the most toxic among metals is cadmium, which can cause a significant degradation of the soil (Smith, 1996; Giller et al., 1998; Renella et al., 2005). Cadmium is widely found in the geosphere; its concentration varies in the range of $0.1-11 \mathrm{mg} \mathrm{kg}^{-1}$. Anthropogenic activity may lead to a multiple increase of its content in the soil (Moreno et al., 2009; Park et al., 2011; Vig et al., 2003).

The functioning of the soil microbial community defines its productivity and fertility in general. The flow of energy passing through the soil microflora is regulated by biosynthetic processes and steady state maintenance. Both processes are influenced by environmental factors, such as the availability of nutrients and the presence of toxicants. The most commonly used parameters enabling to characterize the intensity of the anabolic and catabolic processes carried out by microorganisms include microbial biomass, fixation of atmospheric nitrogen, respiratory activity, soil enzymatic activity, the number of individual groups of microorganisms (Brookes, 1995; Chander and Brookes, 1991; 1992; Moreno et al., 2001; 2002; Renella et al., 2005; Tejada et al., 2011; Vig et al., 2003). When considering such metal as cadmium, it is noted that this metal either alone or in combination with other metals causes a change in the microbial community parameters, at that the authors suggest a wide range of concentrations causing adverse effect-from 0.1-1 to $4.000 \mathrm{mg} \mathrm{kg}$ (Vig et al., 2003). It should be mentioned that until now the authors mainly evaluated the effects of exposure to metals of individual enzymes or processes in the soil that is the activity of certain groups of microorganisms. More recently, some methods have been developed to assess the cumulative effects of exposure to toxicants.

Thus, the aim of this study was to evaluate the effects of cadmium on the growth characteristics and physiological changes in the microbial community profile in gray forest soil. 


\section{Materials and Methods}

The object of the study was the soil microbial communities selected in the area of the Alekseyevskiy municipal district of the Republic of Tatarstan. The soil was characterized by the following parameters: $\mathrm{C}_{\text {org }}$ $6.7 \%, \mathrm{~N}_{\text {total }}-0.15 \%, \mathrm{pH}-6.7$, particle size distributionsand $-40.5 \%$, dust $-54.1 \%$, clay $-5.5 \%$.

To simulate the processes of change of nutrient and content of toxicants the selected soil was divided into 4 fractions. Glucose with the concentration of $10 \mathrm{~g} \mathrm{~kg}^{-1}$ (concentration used for the community activation) (Anderson and Domsch, 1978; Lin and Brookes, 1999) was brought into the first fraction $(S G)$, cadmium in the form of salt $\mathrm{Cd}\left(\mathrm{NO}_{3}\right)_{2}$ in the amount of $500 \mathrm{mg} \mathrm{kg} \mathrm{mg}^{-1}$ (concentration commensurate with EC50 determined by respiratory activity) (Moreno et al., 2002) was added to the second $(S C d)$ fraction, both compounds in identical concentrations were added to the third sample ( $S G C d$ ), the fourth sample $(S)$ represented soil without bringing into it any additional compounds. Soil samples were incubated for 14 days and then samples were taken for analysis.

Soil community growth properties were established due to the optical density change determined by automated method using the Thermo Scientific Multiskan FS microplate reader. The following operating parameters were used: A wavelength is $620 \mathrm{~nm}$, the interval between readings is $30 \mathrm{~min}$, the background shaking prior to measurement is available, shaking duration is $3 \mathrm{sec}$ and the duration of reading is equal to $72 \mathrm{~h}$. The soil suspension (a 1:10 soil-water ratio) was received in advance. The soil suspension of $20 \mu \mathrm{L}$ (diluted up to 10 times) and $180 \mu \mathrm{L}$ of a liquid medium with glucose $(\mathrm{g} / \mathrm{L})$ were dripped into the wells of the microplate: $\mathrm{KH}_{2} \mathrm{PO}_{4}-3, \mathrm{MgSO}_{4} \cdot 7 \mathrm{H}_{2} \mathrm{O}-0,2$, $\mathrm{NaH}_{2} \mathrm{PO}_{4} \cdot 12 \mathrm{H}_{2} \mathrm{O}-4.5, \quad\left(\mathrm{NH}_{4}\right)_{2} \mathrm{SO}_{4}-1, \quad$ glucose-20. Measuring the optical density value of tested strains by automated method was carried out using operational protocol via the Multiskan FS program. The following parameters: The length of the lag phase of growth and maximum optical density were determined from the curves obtained.

Community-level physiological profile was assessed by the ability of the microbial communities to dispose a range of different carbon sources using the BIOLOG ${ }^{\circledR}$ EcoPlates ${ }^{\mathrm{TM}}$ method (Akmal et al., 2005; Boshoff et al., 2014; Garland and Mills, 1991; Insam and Goberna, 2004). In the test 31 carbon-containing compounds are used which are combined into 6 groups: Amino acids, carbohydrates, carboxylic acids, polymers, amines, amides and phenolic compounds (Wu et al., 2013).

In order to characterize the community-level physiological profile a number of key characteristics were assessed (Boshoff et al., 2014; Button et al., 2015).

Richness of microbial community response in each microplate well- $A W C D$ (the average well color development):

$$
A W C D=\frac{1}{31} \sum_{i=1}^{31}\left(A_{i}-A_{o}\right)
$$

where, $A_{i}$-optical well density $i, A_{o}$-optical density of a sample well.

The amount of substrates consumed $(\mathrm{R})$ was calculated as the total number of normalized wells $\left(A_{i}-A_{o}\right)$, the optical density of which was higher than the 0,25 .

Functional diversity of microbial community determined on the basis of the Shannon diversity index $(H)$ :

$$
H=-\sum p_{i} \ln \left(p_{i}\right)
$$

where, $p_{i}$-the ratio of activity of the community to the isubstrate to the amount of activities of communities to all substrates.

Defining all the parameters was performed at least five times repeatedly. Statistical analysis of results was performed using Origin 8.0 software package. The reliability of differences of the results obtained was assessed using Student's criterion $(p<0.05)$.

\section{Results}

The data of the growth of microbial communities of the soil samples on glucose medium are presented in Fig. 1.

The $\mathrm{S}$ community adaptation to the new conditions occurred for $32 \mathrm{~h}$ and the maximum optical density during the growth amounted to be $0.6 \mathrm{AU}$. When analyzing the growth of the $S G$ sample community it was revealed that the growth of the microbial community begins in $18 \mathrm{~h}$. By the $56-60 \mathrm{~h}$ of the growth the microorganism community amounts to a maximum (optical density $=1.45-1.5 \mathrm{AU}$ ). Adding cadmium to soil ( $S C d$ sample) resulted in prolonged lag time of growth of the microbial community in comparison with the original soil, which equaled to $38 \mathrm{~h}$. Further a slight increase in the optical density was observed, which, even by the end of the incubation did not exceed $0.4 \mathrm{AU}$.

In order to establish whether the functional activity of the community changes, in two maximum different samples- $S G$ and $S C d$ the physiological profile was determined via BIOLOG $^{\circledR}$ EcoPlates $^{\mathrm{TM}}$ method. Based on the data obtained at the initial stage of the experiment, $A W C D, R$ and $\mathrm{H}$ indices were calculated for 24, 48, 72, 96 and 168 h. Figure 2 shows changes of the $A W C D$ index values. At all points of the analysis the parameter values in the $S G$ sample were higher compared with those in the $S C d$ sample. The differences in the values of the index increase with time, reaching a maximum up to $168 \mathrm{~h}$. A similar relationship was revealed in the calculation of the $\mathrm{R}$ index, reflecting the amount of substrates consumed by microorganisms communities (Fig. 3). In both cases, the index values increase during incubation from 1 and 0 at the beginning of the experiment to 28 and 11 up to $168 \mathrm{~h}$ in the $S G$ and $S C d$ 
samples respectively. As seen from the data shown in Fig. 4, the $\mathrm{H}$ index is increased over time in both samples reaching 3.2 and 2.3 respectively in the $S C d$ and $S G$ samples.

On the last step we carried out the comparing of sets of substrates utilized to characterize the microbial diversity of two communities. The community, isolated from the soil fed with glucose up to the 168th day of incubation does not utilize only three substrates-Dl- $\alpha$ Glycerol phosphate, D-glucoseamino acid and ketobutyrate. At the same time the soil community fed with cadmium utilizes only 11 substrates out of 31 . Most actively microorganisms of this community utilized of D-mannitol, methyl pyruvate, Tween 80, phenylethylamine and D-cellobiose.

\section{Discussion}

At the first stage the growth characteristics of soil microbial communities were obtained. For this purpose communities in soil slurries were extracted from the soil, which after the removal of soil particles were grown on glucose medium (Fig. 1).

We observed the long lag phase during the growth of the community of the sample $S$. Such long lag phase of growth may be related to the fact that soil microorganisms are mainly oligotrophic organisms and a sufficiently long time is required to adapt them to a high concentration of organic matter in the growth medium. The shorter length of the lag phase of growth of the community from $S G$ sample is due to the fact that glucose has been previously added to the sample, which led to changes in microbial communities. Thus, in this case, the effect observed may be coupled with either the so-called pre-adaptation of microorganisms, or with a community change in the direction of organisms resistant to the high content of organic matter.

The revealed effect of prolongation of lag-phase of sample $S G C d$ is due to the action of such toxic metal as cadmium. Most likely, the introduction of cadmium into the soil leads to the community rearrangement: Firstly, the number of organisms that are sensitive to the action of metal decreases in the soil, the number of resistant organisms increases. Perhaps resistant species are slowgrowing organisms. The second possibility is the overall decline in the number of organisms. Data obtained in the analysis of the growth of the microbial community in the soil, in which both glucose and cadmium were added, are of great interest. As can be seen from the data obtained, the length of the lag phase of growth was lower than for the $S G$ soil, but higher than for the $S C d$ soil. In this case, most likely the effect observed is the result of still more complex processes in the soil. On the one hand, the introduction of glucose stimulates the development of organisms, changing dormant forms into active forms; on the other hand, the toxic metal inhibits processes until the death and elimination of the separate groups of microorganisms. The negative effect of metals and cadmium, in particular, has been described in publications (Akmal et al., 2005; Bérarda et al., 2014; Moreno et al., 2001; 2002; Park et al., 2011; Renella et al., 2005; Vig et al., 2003). Thus, changes in growth characteristics of microbial communities isolated from soil samples fed with cadmium or glucose may indicate a change in the original community. Such changes may be either a reduction in the activity of native microorganisms, or the change in the functional activity of the community, which in turn may be the result of its structure changes.

For the purpose of determination of the functional activity of the communities and also the microbial diversity the physiological profile of the communities was used to define by BIOLOG ${ }^{\circledR}$ EcoPlates $^{\mathrm{TM}}$ (Akmal et al., 2005; Gagliardi et al., 2001; Preston-Mafham et al., 2002).

In order to establish whether the functional activity of the community was changed we compared two maximum different samples-SG and $S C d$ (Fig. 2-4).

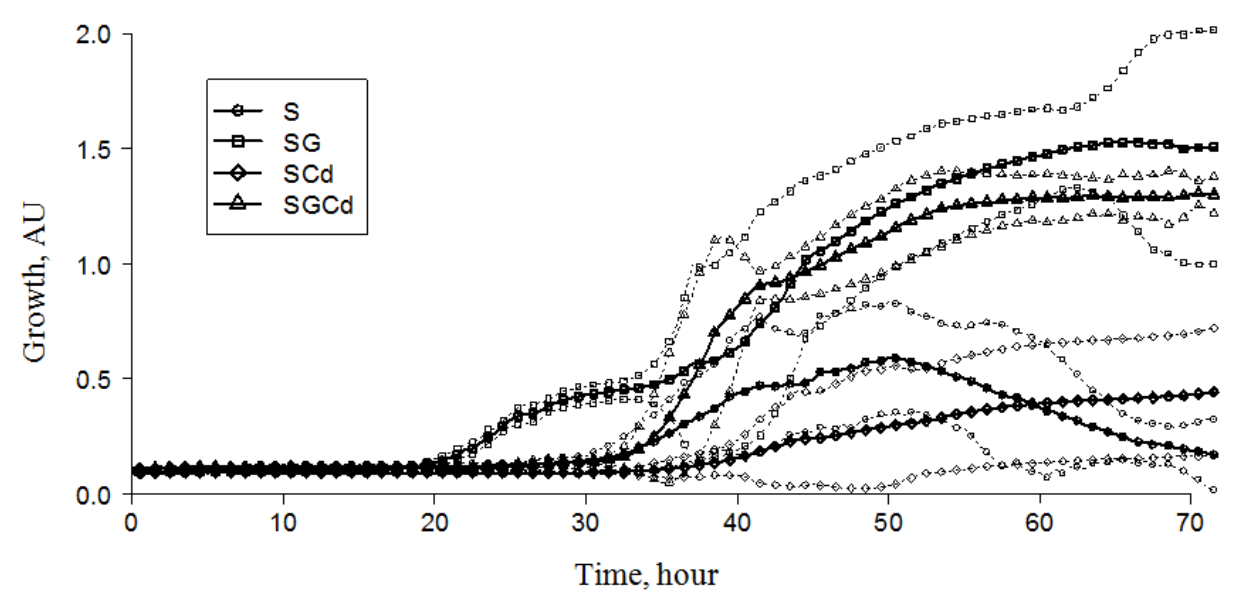

Fig. 1. Growth curves of microbial communities of the soil samples on the glucose medium. The figure shows the mean values for each variant and a $95 \%$ confidence interval 


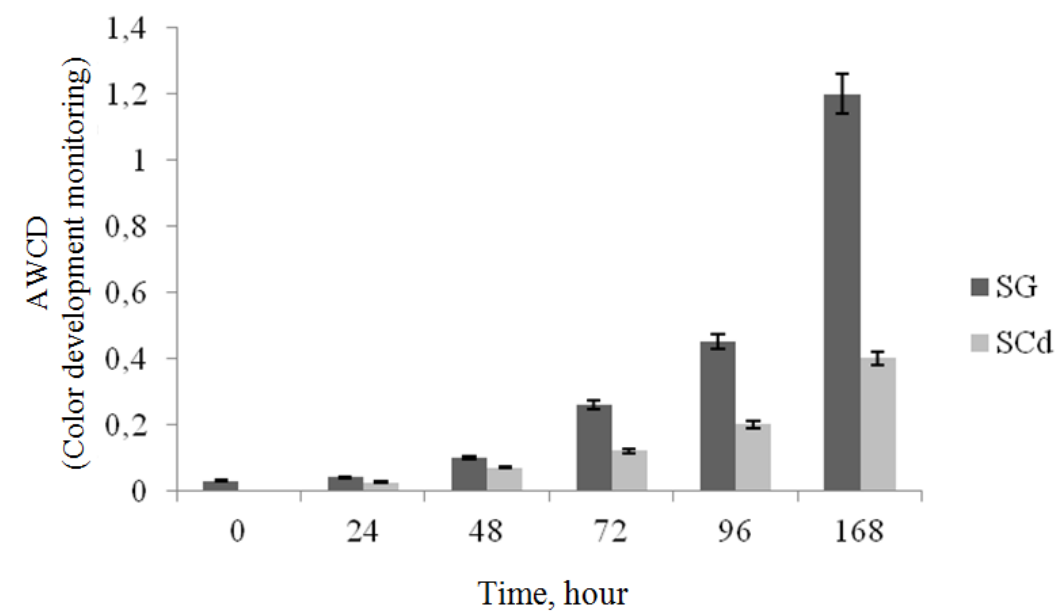

Fig. 2. Average well color development

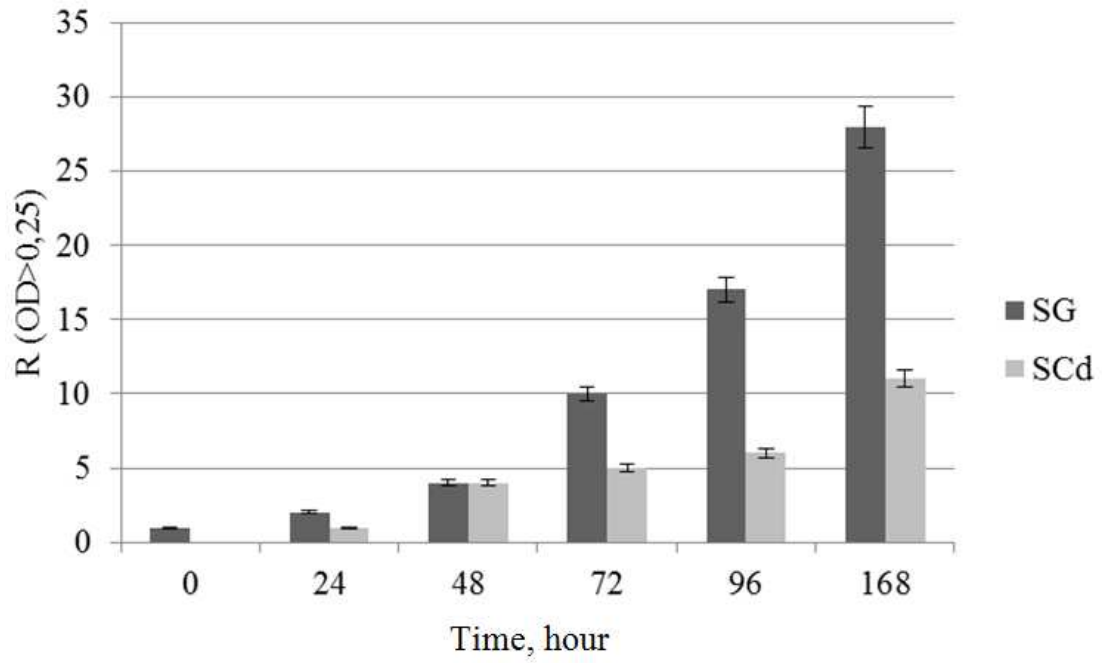

Fig. 3. The development of the amount of substrates consumed

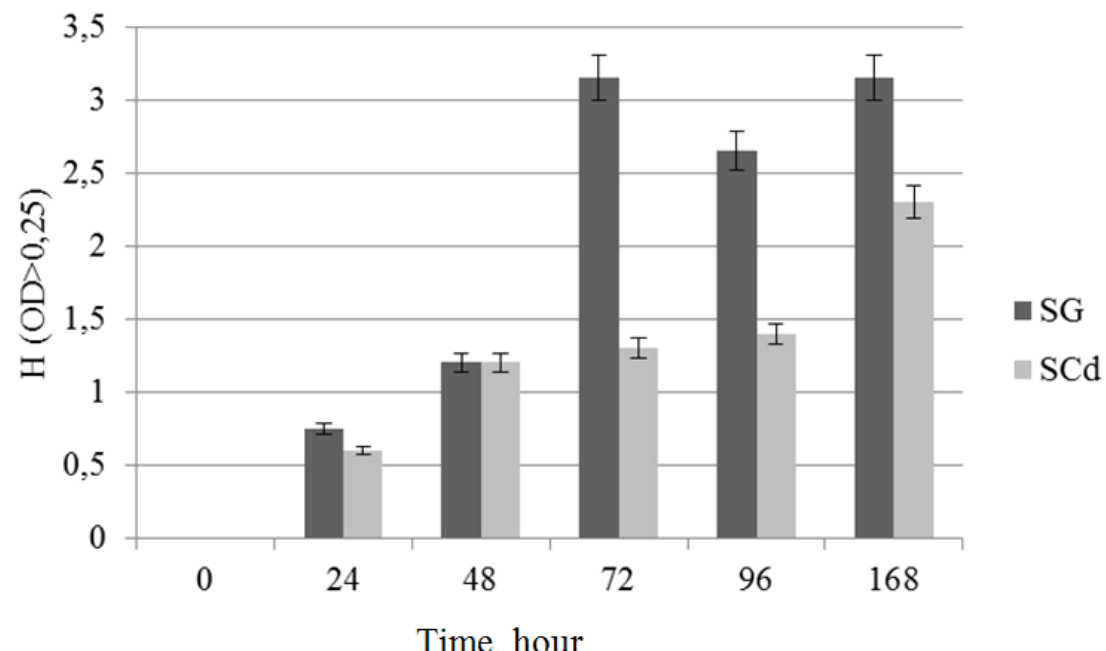

Fig. 4. The development of the community functional diversity 
Data analysis of physiological profile of two samples analyzed gives indirect evidence of differences in the functional activity of the samples under study. Definitely lower indexes values in $S C d$ samples indicate a lower functional diversity in this variant. This is likely due to the fact that cadmium has a negative influence on the microbial community composition, resulting in a change of functions. Microbial diversity is an important indicator of the normal state of ecosystems (Boshoff et al., 2014; Bowles et al., 2014). At the same time the role that biodiversity plays in their functioning is being extensively discussed in publications. So a number of authors are of the opinion that there is an excessive amount of specimen in ecosystem, which can perform the same functions (Nannipieri et al., 2003).

In this case, after a certain time, which is required for activating species resistant to the impact, the community characteristics aligned with the reference performances (Bowles et al., 2014; Nielsen et al., 2011). At the same time, some publications give evidence in that the loss of some key species may have unexpected effects (Hol et al., 2010). In our case, the values of all indices increased over time, at that with no significant differences between the two variants are found only for the $H$ index at definite points of incubation. For two indices, $A W C D$ and $R$, the values of the differences between them remained significant. Thus, we reiterate the assertion that biological diversity is an important factor to maintain and improve the system functioning.

\section{Conclusion}

The above parameters are usually calculated in the analysis of results of the physiological profile assessment to compare two or more communities (Akmal et al., 2005; Boshoff et al., 2014; Button et al., 2015; Garau et al., 2007; Wu et al., 2013). These indicators take into account in one way or another, the amount of utilized organic substrates and the utilization intensity. At the same time, in our view the qualitative analysis, i.e., comparing a set of recyclable substrates, is necessary to characterize the microbial diversity. This is due to the fact that the amount of substrate utilized can be the same, but differ in their selection. In this case, it is obvious that communities are different. That is why we compared the sets of substrates utilized by two communities on the 168th day of incubation. We observed the differences in substrate sets and this confirmed the data on differences in communities formed under the influence of cadmium and glucose.

\section{Acknowledgement}

Authors thank members of OpenLab "Biocontrol" of Kazan Federal University for the excellent work.

\section{Funding Information}

This work was supported by the grant 15-04-04520 of the Russian Foundation of Basic Research.

\section{Author's Contributions}

Aliya Gilmullina: Conducted experimental work.

Polina Galitskaya: Designed the research plan and organized the study.

Svetlana Selivanovskaya: Participated in all experiments, coordinated the data-analysis and contributed to the writing of the manuscript.

\section{Ethics}

The authors have no conflicts of interest in the development and publication of current research.

\section{References}

Akmal, M., X. Jianming, Z. Li, H. Wang and H. Yao, 2005. Effects of lead and cadmium nitrate on biomass and substrate utilization pattern of soil microbial communities. Chemosphere, 60: 508-514. DOI: 10.1016/j.chemosphere.2005.01.001

Anderson, J.P.E. and K.H. Domsch, 1978. A physiological method for the quantitative measurement of microbial biomass in soils. Soil Biol. Biochem., 10: 215-221. DOI: 10.1016/0038-0717(78)90099-8

Bérarda, A., C. Mazziac, V. Sappin-Didier, L. Capowiez and Y. Capowieze, 2014. Use of the MicroResp ${ }^{\mathrm{TM}}$ method to assess pollution-induced community tolerance in the context of metal soil contamination. Ecol. Indic., 40: 27-33.

DOI: $10.1016 /$ j.ecolind.2013.12.024

Boshoff, M., M. De Jonge, F. Dardenne, R. Blust and L. Bervoets, 2014. The impact of metal pollution on soil faunal and microbial activity in two grassland ecosystems. Environ. Res., 134: 169-180.

DOI: 10.1016/j.envres.2014.06.024

Bowles, T.M., V. Acosta-Martínez, F. Calderón and L.E. Jackson, 2014. Soil enzyme activities, microbial communities and carbon and nitrogen availability in organic agroecosystems across an intensivelymanaged agricultural landscape. Soil Biol. Biochem., 68: 252-262.

DOI: $10.1016 /$ j.soilbio.2013.10.004

Brookes, P.C., 1995. The use of microbial parameters in monitoring soil pollution by heavy metals. Biol. Fertility Soils, 19: 269-279. DOI: $10.1007 /$ BF00336094

Button, M., J. Nivala, K.P. Weber, T. Aubron and R.A. Müller, 2015. Microbial community metabolic function in subsurface flow constructed wetlands of different designs. Ecol. Eng., 80: 162-171.

DOI: $10.1016 / \mathrm{j}$.ecoleng.2014.09.073 
Chabukdhara, M. and A.K. Nema, 2013. Heavy metals assessment in urban soil around industrial clusters in Ghaziabad, India: Probabilistic health risk approach. Ecotoxicol. Environ. Safety, 87: 57-64. DOI: 10.1016/j.ecoenv.2012.08.032

Chander, K. and P.C. Brookes, 1991. Microbial biomass dynamics during the decomposition of glucose and maize in metal-contaminated and non-contaminated soils. Soil Biol. Biochem., 23: 917-925. DOI: 10.1016/0038-0717(91)90171-F

Chander, K. and P.C. Brookes, 1992. Synthesis of microbial biomass from added glucose in metal-contaminated and non-contaminated soils following repeated fumigation. Soil Biol. Biochem., 24: 613-614. DOI: $10.1016 / 0038-0717(92) 90088-\mathrm{F}$

Christoforidis, A. and N. Stamatis, 2009. Heavy metal contamination in street dust and roadside soil along the major national road in Kavala's region, Greece. Geoderma, 151: 257-263.

DOI: 10.1016/j.geoderma.2009.04.016

Gagliardi, J.V., J.S. Buyer, J.S. Angle and E. RussekCohen, 2001. Structural and functional analysis of whole-soil microbial communities for risk and efficacy testing following microbial inoculation of wheat roots in diverse soils. Soil Biol. Biochem., 33: 25-40. DOI: 10.1016/S0038-0717(00)00110-3

Garau, G., P. Castaldi, L. Santona, P. Deiana and P. Melis, 2007. Influence of red mud, zeolite and lime on heavy metal immobilization, culturable heterotrophic microbial populations and enzyme activities in a contaminated soil. Geoderma, 142: 47-57. DOI: 10.1016/j.geoderma.2007.07.011

Garland, J.L. and A.L. Mills, 1991. Classification and characterization of heterotrophic microbial communities on the basis of patterns of communitylevel sole-carbon-source utilization. Applied Environ. Microbiol., 57: 2351-2359. PMID: 16348543

Giller, K., E. Witter and S. P. McGrath, 1998. Toxicity of heavy metals to microorganisms and microbial processes in agricultural soils: A review. Soil Biol. Biochem, 30: 1389-1414. DOI: $10.1016 / \mathrm{S} 0038-0717(97) 00270-8$

Hol, W.H., W. de Boer, A.J. Termorshuizen, K.M. Meyer, J.H. Schneider and N.M. van Dam et al., 2010. Reduction of rare soil microbes modifies plantherbivore interactions. Ecol. Lett., 13: 292-301. PMID: 20070364

Insam, H. and M. Goberna, 2004. Community level physiological profiles (Biolog. substrate use tests) of environmental samples. Molecular Microbial. Ecol. Manual, 1: 853-860.

Kelepertzis, E., 2014. Accumulation of heavy metals in agricultural soils of Mediterranean: Insights from Argolida basin, Peloponnese, Greece. Geoderma, 221-222: 82-90.

DOI: $10.1016 /$ j.geoderma.2014.01.007
Lin, Q. and P.C. Brookes, 1999. An evaluation of the substrate-induced respiration method. Soil Biol. Biochem., 31: 1969-1983. DOI: 10.1016/S0038-0717(99)00120-0

Moreno, J.L., C. Garcia, L. Landi, L. Falchini and G. Pietramellara et al., 2001. The ecological dose value $\left(\mathrm{ED}_{50}\right)$ for assessing Cd toxicity on ATP content and dehydrogenase and urease activities of soil. Soil Biol. Biochem., 33: 483-489. DOI: $10.1016 / \mathrm{S} 0038-0717(00) 00189-9$

Moreno, J.L., F. Bastida, M. Ros, T. Hernández and C. Garcia, 2009. Soil organic carbon buffers heavy metal contamination on semiarid soils: Effects of different metal threshold levels on soil microbial activity. Eur. J. Soil Biol., 45: 220-228.

DOI: 10.1016/j.ejsobi.2009.02.004

Moreno, J.L., T. Hernandez, A. Perez and C. Garcia, 2002. Toxicity of cadmium to soil microbial activity: Effect of sewage sludge addition to soil on the ecological dose. Applied Soil Ecol., 21: 149-158. DOI: 10.1016/S0929-1393(02)00064-1

Nannipieri, P., J. Ascher, M.T. Ceccherini, L. Landi and G. Pietramellara et al., 2003. Microbial diversity and soil functions. Eur. J. Soil Sci., 54: 655-670. DOI: 10.1046/j.1351-0754.2003.0556.x

Nielsen, U.N., E. Ayres, D.H. Wall and R.D. Bardgett, 2011. Soil biodiversity and carbon cycling: A review and synthesis of studies examining diversityfunction relationships. Eur. J. Soil Sci., 62: 105-116. DOI: $10.1111 /$ j.1365-2389.2010.01314.x

Park, J.H., J. Lamb, P. Paneerselvam, G. Choppala and N. Bolan et al., 2011. Role of organic amendments on enhanced bioremediation of heavy metal(loid) contaminated soils. J. Hazard Mater., 185: 549-574. DOI: 10.1016/j.jhazmat.2010.09.082

Preston-Mafham, J., L. Boddy and P.F. Randerson, 2002. Analysis of microbial community functional diversity using sole-carbon-source utilisation profilesa critique. FEMS Microbiol. Ecol., 42: 1-14. DOI: 10.1111/j.1574-6941.2002.tb00990.x

Renella, G., M. Mench, L. Landi and P. Nannipieri, 2005. Microbial activity and hydrolase synthesis in longterm Cd-contaminated soils. Soil Biol. Biochem., 37 : 133-139. DOI: 10.1016/j.soilbio.2004.06.015

Smith, S.R., 1996. Agricultural Recycling of Sewage Sludge and the Environment. 1st Edn., CAB International, Wallingford, ISBN-10: 0851989802, pp: 382.

Tejada, M., J. Parrado, T. Hernandez and C. Garcia, 2011. The biochemical response to different $\mathrm{Cr}$ and $\mathrm{Cd}$ concentrations in soils amended with organic wastes. J. Hazard Mater, 185: 204-211. DOI: $10.1016 /$ j.jhazmat.2010.09.019

Vig, K., M. Megharaj, N. Sethunathan and R. Naidu, 2003. Bioavailability and toxicity of cadmium to microorganisms and their activities in soil: A review. Adv. Environ. Res., 8: 121-135. DOI: 10.1016/S1093-0191(02)00135-1 
Wei, B. and L. Yang, 2010. A review of heavy metal contaminations in urban soils, urban road dusts and agricultural soils from China. Microchem. J., 94: 99-107. DOI: 10.1016/j.microc.2009.09.014

Wu, L., Z. Li, J. Li, M.A. Khan and W. Huang et al., 2013. Assessment of shifts in microbial community structure and catabolic diversity in response to Rehmannia glutinosa monoculture. Applied Soil Ecol., 67: 1-9. DOI: 10.1016/j.apsoil.2013.02.008
Zhao, L., Y. Xu, H. Hou, Y. Shangguan and F. Li, 2014. Source identification and health risk assessment of metals in urban soils around the Tanggu chemical industrial district, Tianjin, China. Sci. Total Environ., 468-469: 654-662.

DOI: $10.1016 /$ j.scitotenv.2013.08.094 